\title{
Theoretical Study of a Thermophysical Property of Molten Semiconductors
}

\author{
Fathi Aqra and Ahmed Ayyad \\ Department of Chemistry, Faculty of Science and Technology Hebron University, P.O. Box 40, Hebron, West Bank, Palestine \\ Correspondence should be addressed to Fathi Aqra, fathiaqra2009@hotmail.com
}

Received 11 December 2010; Accepted 23 February 2011

Academic Editor: Ludo Froyen

Copyright (๑) 2011 F. Aqra and A. Ayyad. This is an open access article distributed under the Creative Commons Attribution License, which permits unrestricted use, distribution, and reproduction in any medium, provided the original work is properly cited.

This paper deals with theoretical approach to surface tension of molten silicon and germanium, and contributes to this field, which is very important. A theoretical calculation for determining the surface tension of high-temperature semiconductor melts, such as molten silicon and germanium, in the temperature range $1687-1825 \mathrm{~K}$ and $1211-1400 \mathrm{~K}$, respectively, is described. The calculated temperature-dependence surface tension data for both Si and Ge are expressed as $\gamma=876-0.32\left(T-T_{m}\right)$ and $\gamma=571-0.074\left(T-T_{m}\right)\left(\mathrm{mJ} \mathrm{m}^{-2}\right)$, respectively. These values are in consistence with the reported experimental data (720-875 for $\mathrm{Si}$ and $560-632 \mathrm{~mJ} \mathrm{~m}^{-2}$ for $\mathrm{Ge}$ ). The calculated surface tension for both elements decreases linearly with temperature.

\section{Introduction}

High-temperature melts are substances that are solids at room temperature and liquids at the temperature of interest, namely, at high temperatures. They include liquid metals, molten salts, and recently also molten semiconductor materials. Information on the thermophysical properties of these substances is needed not only because of their scientifically interesting behavior but also because of rising interest in modern industrial applications. Data are needed on semiconductor materials for the production of new materials in microgravity. Accurate thermophysical properties of molten semiconductors (silicon and germanium) are important ingredients and are needed for understanding liquid structures, the solidification process, and the numerical modeling of crystal growth processes. However, the measurement of thermophysical properties at high temperatures, such as high-temperature melts of liquid metals is a necessary, but difficult, task.

Although solid silicon and germanium have been extensively investigated, results on the properties of molten Si and Ge are scarce and there are substantial differences between them. The surface tension is sensitive to even minute surface contamination. However, it has been measured for molten silicon and germanium at the melting points [1-7] and at different temperatures [8-12]. The surface tension of high-temperature melts is the most needed and the most poorly established property. It is needed in the study of droplet or surface behavior, in the prediction of Marangoni convection, and it has significant importance in science and recent engineering applications. Control of surface behavior is the key to obtain high-quality single crystals of silicon and germanium from the melt. A study of direct contact heat transfer requires surface tension data in order to predict the behavior of droplets or bubbles. The surface tension of liquid elements is essential from the scientific point of view of validating theories of the liquid state, as well as for practical applications in processing by chemical and metallurgical industries [13] such as casting, molding, refining, sintering, and crystal growth operations [14].

In extension to the earlier work [15-17], this paper presents a theoretical calculation of the temperature dependence surface tension of molten silicon (1687-1825 K) and germanium (1211-1400 K). The model-calculated results showed reasonable consistency with the reported experiment measured. 


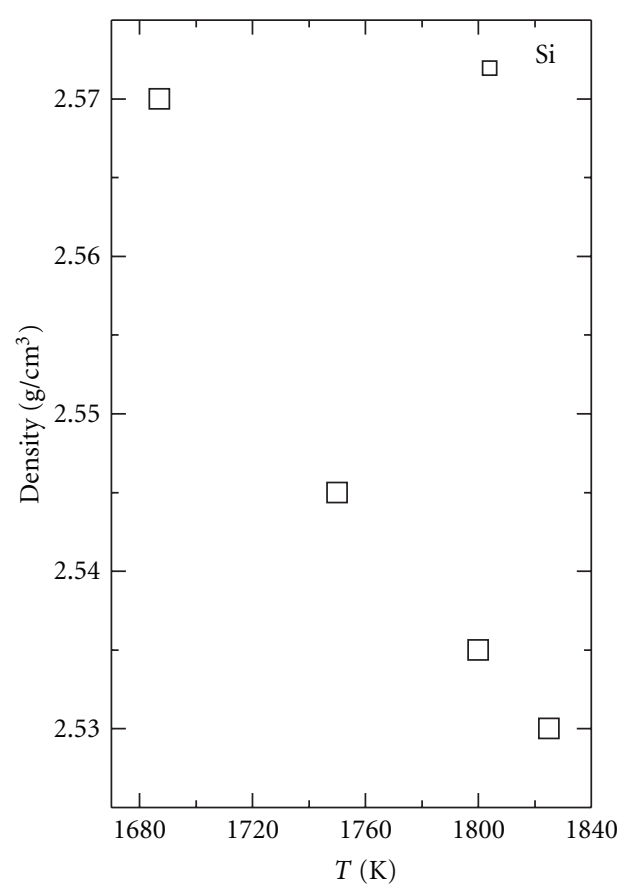

(a)

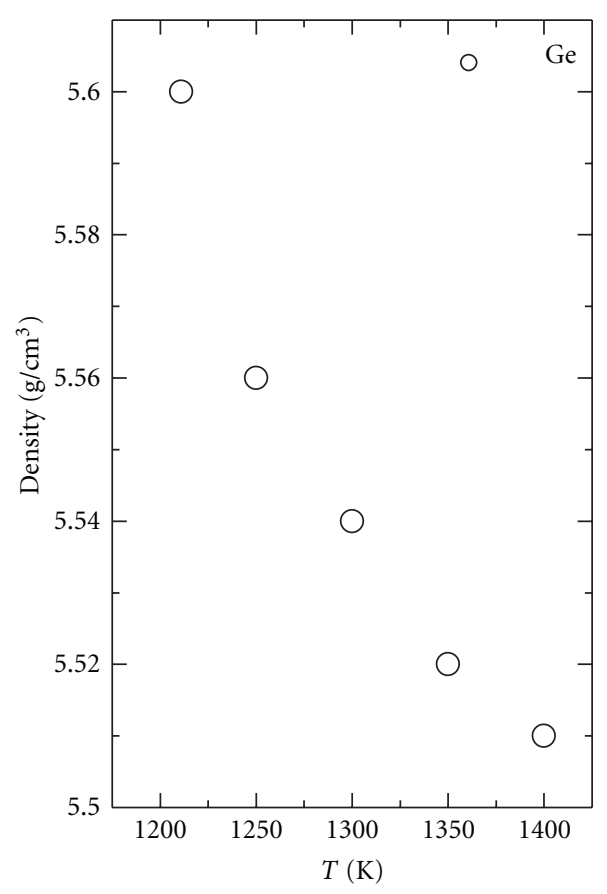

(b)

FIgURe 1: Density as a function of temperature for molten Si and Ge (data taken from [10] for Si and from [11, 22] for Ge).

\section{Theory and Model}

The theoretical consideration is based on classical statistical thermodynamics formulation of Eyring and coworkers [1820]. Their theory is focused on the assumption that the metal upon melting acquires vacancies that are moving freely through the melt, and there is short-range order in the liquid. The thermodynamic properties of the liquid metal may be calculated from the relationship between the Helmholtz free energy and the partition functions. Eyring has shown that this approach can predict the thermodynamic properties of a large number of liquids and pure liquid metals. The Eyring's approach in calculating the surface tension of a liquid metal was made by Schoutens [21], who calculated the surface tension of pure liquid $\mathrm{Al}$.

Recently, an equation was derived for calculating the surface tension of pure liquid metals [15-17]. This equation may be applied for surface tension calculations of a nonmetal and a metalloid such as molten silicon and germanium. The equation has the following form:

$$
\gamma=\varphi^{-1}\left(\frac{V_{s}}{V}\right)^{2} k T\left[\frac{E_{s}}{R T}(1-3 f)+\frac{3}{2} \ln \frac{3}{4}(1+f)\right],
$$

where $\gamma$ is surface tension $\left(\mathrm{mJ} \mathrm{m}^{-2}\right), \varphi$ is the area occupied by one atom $\left(\mathrm{cm}^{2}\right.$ atom $\left.{ }^{-1}\right)$ given by $\varphi=(\sqrt{3} / 2)\left(\sqrt{2} V_{s} / N\right)^{2 / 3}$, where $N$ is Avogadro number $\left(6.02 .10^{23}\right.$ atoms $\left./ \mathrm{mol}\right), V$ and $V_{s}$ are molar volumes $\left(\mathrm{cm}^{3} \mathrm{~mol}^{-1}\right)$ at any temperature and at the melting point, respectively, that are given by $V$ or $V_{s}=M / \rho(T)$, where $M$ is the atomic weight and $\rho(T)$ is the density as a function of temperature, $k$ is the Boltzmann
TABLe 1: Parameters needed for calculations of the surface tension of molten $\mathrm{Si}$ and $\mathrm{Ge}\left(T_{m}\right.$, density, and $E_{s}$ values were taken from [23], while $V_{s}, f$, and $\varphi$ were determined as given in the text).

\begin{tabular}{lcc}
\hline Parameter & $\mathrm{Si}$ & $\mathrm{Ge}$ \\
\hline$T_{m}(\mathrm{~K})$ & 1687 & 1211 \\
Density at m.p. $\left(\mathrm{g} / \mathrm{cm}^{3}\right)$ & 2.57 & 5.60 \\
$E_{s}(\mathrm{~kJ} / \mathrm{mol})$ & 456 & 377 \\
$V_{s}\left(\mathrm{~cm}^{3} / \mathrm{mol}\right)$ & 10.92 & 12.96 \\
$f$ & 0.297 & 0.297 \\
$\varphi\left(\times 10^{-16}\right)$ & 7.53 & 8.44 \\
\hline
\end{tabular}

constant $\left(1.38 .10^{-23} \mathrm{JK}^{-1}\right), T$ is the absolute temperature $(1687-1825 \mathrm{~K}$ for $\mathrm{Si}$ and $1211-1400 \mathrm{~K}$ for $\mathrm{Ge}), E_{s}$ is the sublimation energy $\left(\mathrm{J} \mathrm{mol}^{-1}\right)$, and $R$ is the universal gas constant $\left(8.31 \mathrm{~J} \mathrm{~K}^{-1} \mathrm{~mol}^{-1}\right)$. The $f$ term is a dimensionless constant parameter that describes the fraction of broken bonds (equal to 0.297 for Si and Ge). This value is a positive fractional number and is fixed by the best fit of the results with the experimental measurements for many metals. It has been determined by taking experimental surface tension values of 10 metals at their melting points and its value was varied until the calculated surface tension matches that of the experimental one. Therefore, the main equation calculating surface tension contains a parameter $f$, and the value of $f$ was determined through fitting the equation to the experimental results measured at the melting point. 
TABLE 2: Density and surface tension data for molten Si and Ge.

\begin{tabular}{|c|c|c|c|c|c|}
\hline Element & Temperature $(\mathrm{K})$ & Density $\left(\mathrm{g} / \mathrm{cm}^{3}\right)[10,11]$ & Exp. $\gamma\left(\mathrm{mJ} \mathrm{m}^{-2}\right)[10,11]$ & Exp. $\gamma\left(\mathrm{mJ} \mathrm{m}^{-2}\right)[8,9]$ & Cal. $\gamma\left(\mathrm{mJ} \mathrm{m}^{-2}\right)$ \\
\hline \multirow{4}{*}{$\mathrm{Si}$} & 1687 & 2.57 & 875 & 820 & 876 \\
\hline & 1750 & 2.545 & 851 & 801 & 855 \\
\hline & 1800 & 2.535 & 808 & 786 & 839 \\
\hline & 1825 & 2.530 & 779 & 778 & 831 \\
\hline \multirow{5}{*}{$\mathrm{Ge}$} & 1211 & 5.60 & 583 & 591 & 572 \\
\hline & 1250 & 5.56 & 579 & 587 & 568 \\
\hline & 1300 & 5.54 & 576 & 583 & 562 \\
\hline & 1350 & 5.52 & 571 & 579 & 558 \\
\hline & 1400 & 5.51 & 568 & 575 & 556 \\
\hline
\end{tabular}

Density and measured surface tension data were taken from [8-11]. Note that $\mathrm{mJ} \mathrm{m}^{-2}=$ dynes $\mathrm{cm}^{-1}=\mathrm{mN} \mathrm{m}^{-1}$.

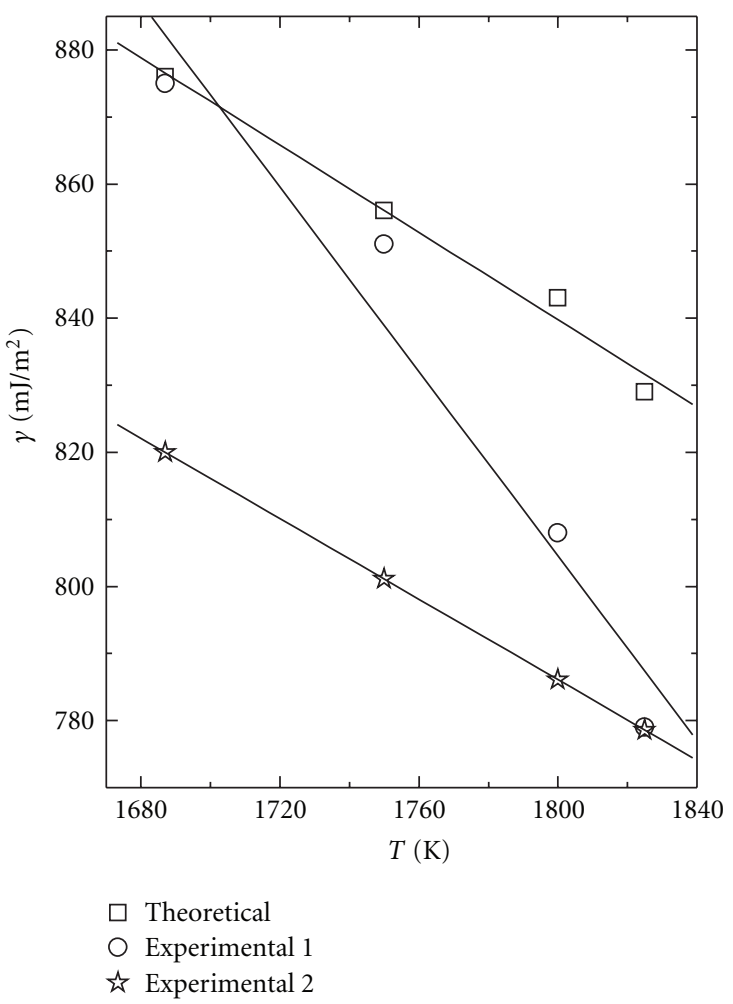

Figure 2: The calculated and the measured temperature-dependence of the surface tension of molten $\mathrm{Si}$ (open squares are our results, open circles are reported experimental data 1 taken from [10] and stars are reported experimental data 2 taken from [8]). $\gamma=876-0.32\left(T-T_{m}\right)\left(\mathrm{mJ} \mathrm{m}^{-2}\right)$ (our data, theoretical), $\gamma=$ $875-0.68\left(T-T_{m}\right)\left(\mathrm{mJ} \mathrm{m}^{-2}\right)($ experimental $1[10])$ and $\gamma=$ $820-0.3\left(T-T_{m}\right)\left(\mathrm{mJ} \mathrm{m}^{-2}\right)$ (experimental $\left.2[8]\right)$.

\section{Calculations and Discussion}

The sublimation energy, molar volume and other parameters needed to calculate the surface tension are illustrated in Table 1 [23]. The molar volumes, $V$, were calculated using the reported experimental temperature-dependence density data of molten Si and $\mathrm{Ge}[10,11]$. The data in these references are shown in Figure 1 and in Table 2. It is clear that the density is monotonically decreasing and almost

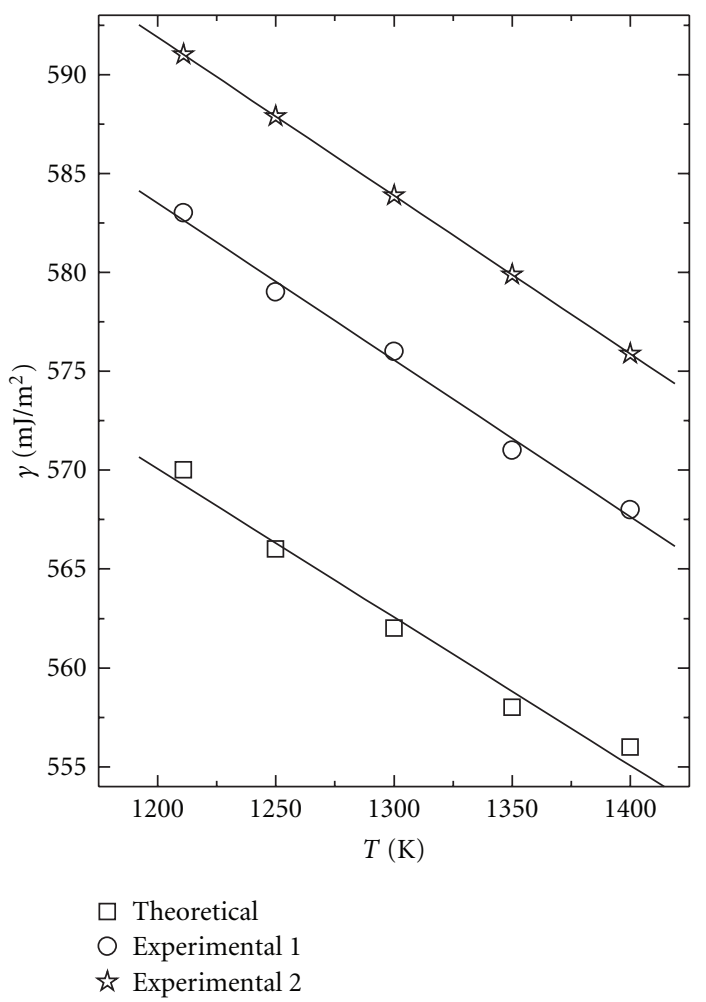

FIGURE 3: The calculated and the measured temperature-dependence of the surface tension of molten Ge (open squares are our results, open circles are reported experimental data 1 taken from [11] and stars are reported experimental data 2 taken from $[9,22])$. $\gamma=571-0.074\left(T-T_{m}\right)\left(\mathrm{mJ} \mathrm{m}^{-2}\right)$ (our data, theoretical), $\gamma=$ $583-0.079\left(T-T_{m}\right)\left(\mathrm{mJ} \mathrm{m}^{-2}\right)($ experimental $1[11])$ and $\gamma=$ $591-0.08\left(T-T_{m}\right)\left(\mathrm{mJ} \mathrm{m}^{-2}\right)$ (experimental $\left.2[9]\right)$.

a linear function with the temperature. Table 2 shows the density as well as calculated and reported experimental surface tension data as a function of temperature for both of the molten elements. According to our calculations, the resulting theoretical function showed a decreasing function in the temperature range $1687-1825 \mathrm{~K}$ and $1211-1400 \mathrm{~K}$ for molten Si (Figure 2) and Ge (Figure 3), respectively. However, Figures 2 and 3, and Table 2 show a comparison between the experimental values of the surface tension for 
molten Si and Ge [8-11] and the calculated ones as a function of temperature. The solid lines present the best linear least square fitting. It is observed that there is a similar decrease of the surface tension as a function of temperature both theoretically and experimentally. As reported, the recommended surface tension at different temperature for Si [8] is $\gamma=820-0.3\left(T-T_{m}\right)\left(\mathrm{mJ} \mathrm{m}^{-2}\right)$, while for Ge [9], $\gamma=591-0.08\left(T-T_{m}\right)\left(\mathrm{mJ} \mathrm{m}^{-2}\right)$. Also, Rhim and Ishikawa fitted their surface tension data for molten $\mathrm{Ge}$ [11] as: $\gamma=583-0.08\left(T-T_{m}\right)\left(\mathrm{mJ} \mathrm{m}^{-2}\right)$, and for molten Si $[10,24]$ as: $\gamma=875-0.22\left(T-T_{m}\right)\left(\mathrm{mJ} \mathrm{m}^{-2}\right)$ and $\gamma=765-0.016\left(T-T_{m}\right)\left(\mathrm{mJ} \mathrm{m}^{-2}\right)$. The calculated surface tension data show good agreement and are expressed as:

(i) for molten silicon, $\gamma=876-0.32\left(T-T_{m}\right)\left(\mathrm{mJ} \mathrm{m}^{-2}\right)$,

(ii) for molten germanium, $\gamma=571-0.074\left(T-T_{m}\right)$ $\left(\mathrm{mJ} \mathrm{m}^{-2}\right)$.

Figures 2 and 3 reveal that there is about $6 \%$ and $4 \%$ difference beween the calculated and the experimental results for Si and Ge, respectively. This may be attributed to the fact that the surface tension of molten silicon and germanium is difficult to measure accurately, and consequently, the available experimental data for the surface tension of molten silicon [1-5] and molten germanium [5-7] is currently widely scattered, not only their absolute values but also their temperature dependence, and agreement between the existing experimental data is quite poor (for $\mathrm{Si}, \gamma$ ranges from 720 to $875 \mathrm{~mJ} / \mathrm{m}^{2}$, whereas the range is $560-632 \mathrm{~mJ} / \mathrm{m}^{2}$ for $\mathrm{Ge}$ ). The data reported in the literature suffer from experimental problems and the presence of impurities. Most often, the surface tension is strongly affected by surface active impurities such as oxygen, and so strongly dependent on the oxygen concentration in the liquid phase. The experimental measurements of this property is extremely difficult at high temperatures because surface tension is very sensitive to physical and chemical interactions. The difficulties are due to strong reactivity of the sample with container walls, rapid degradation of the samples, effect of electrical conductivity on sensors, sensitive impurity effects, and occurrence of supercooling and non Newtonian behavior near the melting temperature. The theoretical prediction of the surface tension of silicon is higher than the experimental values and lower for germanium because $\mathrm{Si}$ is a nonmetal, and thus, it is less sensitive than Ge to environmental effects.

The calculated surface excess entropy $(-d \gamma / d T)$ from the slope of the theoretical graphs $\left(0.32\right.$ and $0.074 \mathrm{~mJ} \mathrm{~m}^{-2} \mathrm{~K}^{-1}$ for $\mathrm{Si}$ and Ge, resp.) is close to the reported experimental values (for Si; 0.22 [10], 0.28 [25], 0.308 [26] and 0.65 [27], and $0.08 \mathrm{~mJ} \mathrm{~m}^{-2} \mathrm{~K}^{-1}$ for Ge [11]). However, our results may be strictly compared with experimental surface tension data, as a function of temperature for molten $\mathrm{Si}$ and $\mathrm{Ge}$, reported by others [22, 28-32]. Therefore, the model looks acceptable and predicts the same order of magnitude values for the temperature dependence of the surface tension of metals $(\mathrm{Ga})$, metalloids $(\mathrm{Ge})$, and nonmetals $(\mathrm{Si})$.

\section{Conclusion}

This paper applies a previously developed equation to theoretically predict the surface tension of liquid silicon and germanium. The predictions are in satisfactory agreement with available experimental data and the theoretical calculation greatly supports the experimental observations. The result is very important and can provide additional insight for the understanding of the physical and chemical properties of silicon and germanium.

\section{References}

[1] T. Hawa and M. R. Zachariah, "Internal pressure and surface tension of bare and hydrogen coated silicon nanoparticles," Journal of Chemical Physics, vol. 121, no. 18, pp. 9043-9049, 2004.

[2] H. Nakanishi, K. Nakazato, and K. Terashima, "Surface tension variation of molten silicon measured by ring tensiometry technique and related temperature and impurity dependence," Japanese Journal of Applied Physics, vol. 39, no. 12, pp. 64876492, 2000.

[3] B. J. Keene, "Review of the surface tension of silicon and its binary alloys with reference to marangoni flow," Surface and Interface Analysis, vol. 10, no. 8, pp. 367-383, 1987.

[4] H. Fujii, T. Matsumoto, S. Izutani, S. Kiguchi, and K. Nogi, "Surface tension of molten silicon measured by microgravity oscillating drop method and improved sessile drop method," Acta Materialia, vol. 54, no. 5, pp. 1221-1225, 2006.

[5] P. H. Keck and W. Van Horn, "The surface tension of liquid silicon and germanium," Physical Review, vol. 91, no. 3, pp. 512-513, 1953.

[6] H. Nakanishi, K. Nakazato, S. Asaba, K. Abe, S. Maeda, and K. Terashima, "Ring depression technique for measuring surface tension of molten germanium," Journal of Crystal Growth, vol. 187, no. 3-4, pp. 391-396, 1998.

[7] R. C. Sangster and J. N. Carman, "Liquid surface tension measurements by analysis of solid-state curvatures; the surface tension of liquid germanium," The Journal of Chemical Physics, vol. 23, no. 6, pp. 1142-1145, 1955.

[8] A. V. Shishkin and A. S. Basin, "Surface tension of liquid silicon," Theoretical Foundations of Chemical Engineering, vol. 38, no. 6, pp. 660-668, 2004.

[9] N. Kaiser, A. Cröll, F. R. Szofran, S. D. Cobb, and K. W. Benz, "Wetting angle and surface tension of germanium melts on different substrate materials," Journal of Crystal Growth, vol. 231, no. 4, pp. 448-457, 2001.

[10] W. K. Rhim, S. K. Chung, A. J. Rulison, and R. E. Spjut, "Measurements of thermophysical properties of molten silicon by a high-temperature electrostatic levitator," International Journal of Thermophysics, vol. 18, no. 2, pp. 459-469, 1997.

[11] W. K. Rhim and T. Ishikawa, "Thermophysical properties of molten germanium measured by a high-temperature electrostatic levitator," International Journal of Thermophysics, vol. 21, no. 2, pp. 429-443, 2000.

[12] A. Nagashima, "Viscosity, thermal conductivity, and surface tension of high-temperature melts," International Journal of Thermophysics, vol. 11, no. 2, pp. 417-432, 1990.

[13] R. P. Chhabra and D. K. Sheth, "Viscosity of molten metals and its temperature dependence," Zeitschrift fuer Metallkunde, vol. 81, no. 4, pp. 264-271, 1990.

[14] I. Egry and S. Sauerland, "Containerless processing of undercooled melts: measurements of surface tension and viscosity," 
Materials Science and Engineering A, vol. 178, no. 1-2, pp. 7376, 1994.

[15] A. Ayyad and F. Aqra, "Theoretical consideration of the anomalous temperature dependence of the surface tension of pure liquid gallium," Theoretical Chemistry Accounts, vol. 127, no. 5, pp. 443-448, 2010.

[16] F. Aqra and A. Ayyad, "Surface tension of pure liquid bismuth and its temperature dependence: theoretical calculations," Materials Letters, vol. 65, no. 4, pp. 760-762, 2011.

[17] F. Aqra and A. Ayyad, "Theoretical calculations of the surface tension of liquid transition metals," Metallurgical and Materials Transactions B, vol. 42, no. 1, pp. 5-8, 2011.

[18] T. S. Ree, T. Ree, and H. Eyring, "Significant structure theory of surface tension," The Journal of Chemical Physics, vol. 41, no. 2, pp. 524-530, 1964.

[19] W. C. Lu, M. U. S. Jhon, T. Ree, and H. Eyring, "Significant structure theory applied to surface tension," The Journal of Chemical Physics, vol. 46, no. 3, pp. 1075-1081, 1967.

[20] H. Eyring and M. S. Jhon, Significant Liquid Structure, John Wiley \& Sons, New York, NY, USA, 1969.

[21] J. E. Schoutens, "Some theoretical considerations of the surface tension of liquid metals for metal matrix composites," Journal of Materials Science, vol. 24, no. 8, pp. 2681-2686, 1989.

[22] A. Ishikura, A. Mizuno, M. Watanabe, T. Masaki, T. Ishikawa, and S. Yoda, "Structure and thermophysical properties of molten BaGe using electrostatic levitation technique," International Journal of Thermophysics, vol. 29, no. 6, pp. 2015-2024, 2008.

[23] C. E. Housecroft and A. C. Sharpe, Inorganic Chemistry, Pearson Education, Essex, UK, 1st edition, 2001.

[24] W. K. Rhim and K. Ohsaka, "Thermophysical properties measurement of molten silicon by high-temperature electrostatic levitator: density, volume expansion, specific heat capacity, emissivity, surface tension and viscosity," Journal of Crystal Growth, vol. 208, no. 1, pp. 313-321, 2000.

[25] S. C. Hardy, "The surface tension of liquid silicon," Journal of Crystal Growth, vol. 69, no. 2-3, pp. 456-460, 1984.

[26] S. I. K. Chung, K. Izunome, A. Yokotani, and S. Kimura, "Estimation of surface tension of molten silicon using a dynamic hanging drop," Japanese Journal of Applied Physics, vol. 34, no. 5, pp. L631-L634, 1995.

[27] M. Przyborowski, T. Hibiya, M. Eguchi, and I. Egry, "Surface tension measurement of molten silicon by the oscillating drop method using electromagnetic levitation," Journal of Crystal Growth, vol. 151, no. 1-2, pp. 60-65, 1995.

[28] W. D. Kingery and M. Humenik, "Surface tension. At elevated temperatures. I. Furnace and method for use of the sessile drop method; surface tension of silicon, iron and nickel," Journal of Physical Chemistry, vol. 57, no. 3, pp. 359-363, 1953.

[29] S. Nakamura and T. Hibiya, "Thermophysical properties data on molten semiconductors," International Journal of Thermophysics, vol. 13, no. 6, pp. 1061-1084, 1992.

[30] T. Hibiya and S. Nakamura, "Thermophysical property measurements on molten semiconductors using 10-s microgravity in a drop shaft," International Journal of Thermophysics, vol. 17, no. 5, pp. 1191-1201, 1996.

[31] T. Hibiya and I. Egry, "Thermophysical property measurements of high temperature melts: results from the development and utilization of space," Measurement Science and Technology, vol. 16, no. 2, pp. 317-326, 2005.

[32] H. M. Lu, T. H. Wang, and Q. Jiang, "Surface tension and selfdiffusion coefficient of liquid Si and Ge," Journal of Crystal Growth, vol. 293, no. 2, pp. 294-298, 2006. 

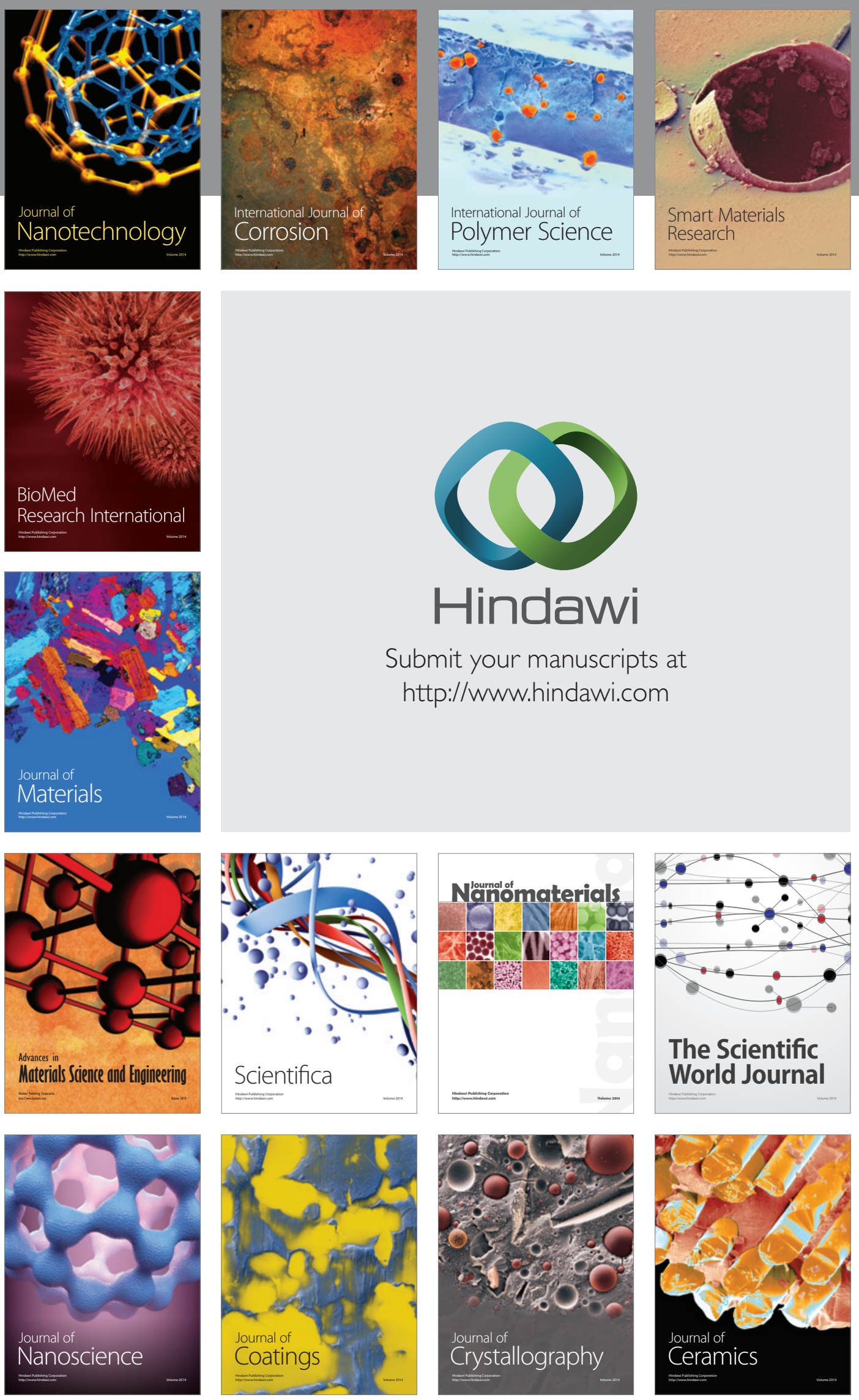

The Scientific World Journal

Submit your manuscripts at

http://www.hindawi.com

\section{World Journal}

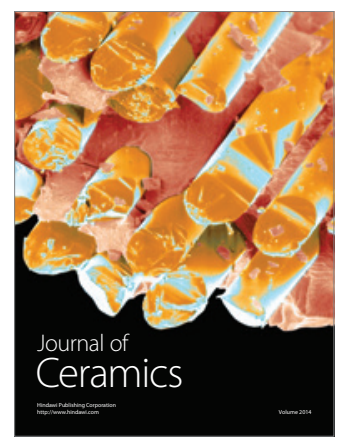

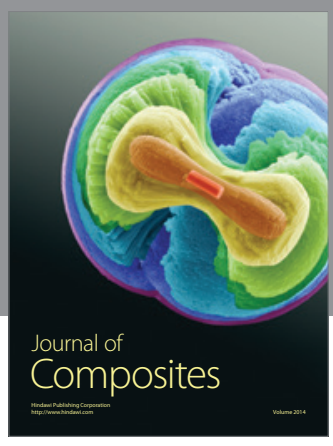
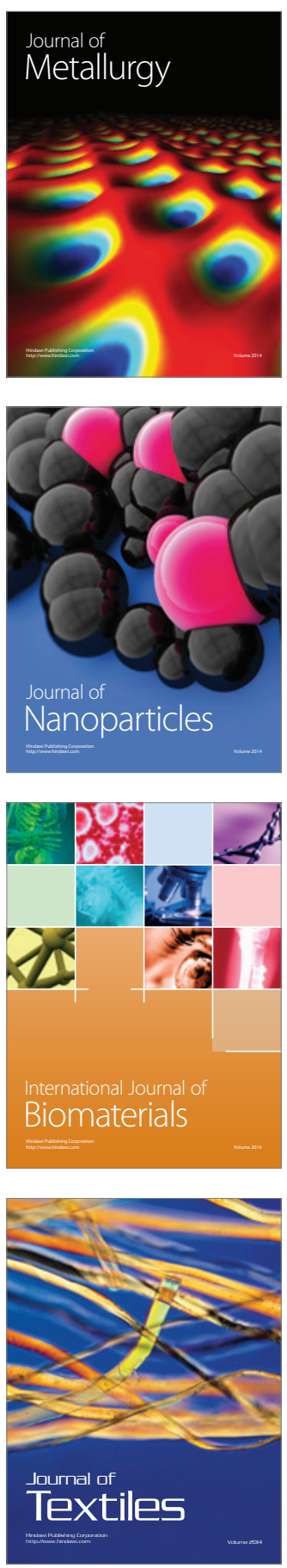